\title{
Purpose and function of IPCC
}

SIR - Your leading article, "Global warming rows" (Nature 378, 322; 1995) displays a misunderstanding of the purpose and functioning of the Intergovernmental Panel on Climate Change (IPCC) and its three working groups. You characterize these three groups as dealing respectively with "questions of climatic evidence, the consequences of warming, and with 'advice to policymakers' ", and you write as though homogenous, closed groups of experts write the reports and the summaries. This is mostly incorrect.

The IPCC is the most extensive and carefully constructed intergovernmental advisory process ever established in international relations. Governments nominate experts - people with proven ac-ademic track records - that then form writing teams selected for breadth of expertise and geographical balance. The three working groups are not in any way constructed to give a linear path from science to impacts to policy advice. Rather, they are concerned with assessing the literature on (1) climate science, (2) technical aspects of impacts and response options, and (3) economic and other cross-cutting issues. The teams write the main chapters (and chapter summaries), which generally go through widespread peer review - with hundreds of people and groups worldwide invited to comment. The content remains under the control of the writing teams.

The 'Policymakers' Summary' is not a technical summary. Although usually drafted by the experts to put all key findings 'on the table', the final text represents a painstakingly negotiated statement of what governments officially accept as a balanced account of the state of knowledge and reasoned judgement, based on the chapters. Governments cannot alter the chapters, and authors cannot alter the Policymakers' Summary. In other fora (the UN Climate Convention) governments will debate appropriate policy responses, and obviously may wield the words they have agreed in the IPCC Policymakers' Summary as ones carrying particular force. But the IPCC is precluded from making any policy recommendations, and as a body does not.

The biggest threat to rational action on climate change is ignorance on the part of governments - ignorance that would find expression in governments choosing their preferred facts and preferred experts to suit national interests or particular pressure groups. The IPCC forms a critical, mutually agreed process to establish a basis of internationally accepted knowledge, and without such a process the negotiations would be rudderless and irrational. And the process of developing IPCC reports plays at least two further roles: it educates government delegates about the findings of research; and it stimulates critical debate between research communities that might otherwise try and ignore each other's existence.

Your suggestion that Working Groups II and III be abandoned is extraordinary. Do you really think that negotiations would proceed better if there were no such assessment of literature on the impacts of climate change, the technical options for mitigation, or of the economic and related analyses surrounding the issue? As it happens, I have sympathy with some of the reservations expressed by governments about some of the literature on valuation of impacts (and valuation of statistical life). But I would defend absolutely both the right of the chapter authors to say what they think, and the right of governments to voice their reservations and concerns. I have had my share of intellectual clashes on other parts of the Working Group III report and the report is not as any of us would have written it alone; but all those involved - authors, government representatives, reviewers and even perhaps a few media commentators - are wiser for the experience.

Of course the IPCC is not perfect. Everyone works under time pressure. Some writing teams turn out not to encompass all valid views, and some may not do full justice to review comments; experts suffer personal preferences and other human faults. Judgements also have to be made about inclusion of important information that reaches publication only in the later stages of the process. Governments could be given a stronger hand in policing all this - but only at the risk of greater politicization of the reports. Similarly, authors could be given stronger power over the Policymakers' Summary - but only at the cost of reducing its political authority and relevance as a governmentally agreed document. Like democracy, the IPCC is far from perfect, but I have yet to see a better system of advice in international affairs

\section{Michael Grubb}

(Lead Author, Working Group III)

Energy and Environmental Programme, Royal Institute of International Affairs,

Chatham House,

10 St James's Square,

London SW1Y 4LE,UK

SIR - I should like to clarify the situation in response to your reporting on Working Group 3 (WG3) of the IPCC (Nature 378, $119 ; 1995$, and subsequent issues).

In the IPCC procedures established by the governments, lead authors prepare technical assessments of published litera- ture on an agreed range of topics. These reports are subject to peer and government reviews. The government representatives then have an opportunity to select from these technical reports those findings of special relevance to policy-makers, or in some instances to comment on the findings. This results in a Summary for Policy Makers (SPM), which is the responsibility of government representatives to the working group. The technical reports remain the responsibility of the lead authors.

In the case of WG3, at plenary meetings of more than 70 country representatives and a number of non-governmental organizations (NGOs) in Geneva (25-28 July 1995) and Montreal (11-13 October 1995), an SPM was approved line by line, and the technical report, including all chapters, was accepted.

There was some contention, as you have reported, about matters contained in Chapter 6, "Social Costs of Climate Change: Greenhouse Damage and the Benefits of Control", as well as several other chapters. In the approved SPM, country representatives expressed concern about the way in which the economics literature treats non-market damages, especially the risk of increased mortality (value of a statistical life). In the SPM they make it clear that "while some regard monetary valuation of such (non-market) impacts as essential to sound decision making, others reject monetary valuation of some impacts, such as risk of human mortality, on ethical grounds". The SPM goes on to express the view that "societies may want to preserve human life in an equal way".

The corresponding technical chapter by the lead authors draws a distinction between a "prescriptive approach" to the value of a statistical life and a "descriptive approach" (Box 6.1). A prescriptive approach asks the question, "at how much ought a statistical life to be valued according to ethical or other criteria?" The authors conclude that "[a]n obvious implication of this approach is that all lives will be treated equally". The text then goes on to outline the "descriptive approach" by which most of the economics literature (in many fields, not just climate change) evaluates the costs that society is willing to incur to protect lives, or "the willingness to pay". Thus, the "ethical" or "prescriptive" approach preferred by country delegates is explicitly recognized in Chapter 6, although the literature available for assessment was based on a descriptive approach. In addition, both Chapter 6 and the SPM make the point that: "For individual nations, or if alternative assumptions are made about the value of a statistical life (damage figures) could be much higher"(wording from Chapter 6). 
Chapter 6 contains a great deal of valuable information to help policy-makers, especially those in developing countries. It provides estimates that show climate change damages in developing countries are likely to be up to 9 times greater, proportionately, than damages to developed countries. It also shows that the net aggregate effects of projected climate change would probably be global damages of the order of a few per cent of gross domestic product. This gives an economic rationale for acting to reduce greenhouse gases that goes beyond energy efficiency and other measures that are worth doing for their own sake. These and other findings in the chapter, and in the balance of the WG3 report, support actions both on greenhouse gas reductions and to assist developing countries. The SPM and chapters have already been cited favourably by the Climate Action Network (Environmental NGOs) in their submission to the Ad Hoc Group on the Berlin Mandate of the Conference of Parties to the Framework Convention on Climate Change.

The final Plenary Session of the IPCC in Rome (11-15 December 1995), with some 120 countries represented, has also accepted unanimously the Summary for Policy Makers and all chapters of WG3 (as well as those of Working Groups 1 and 2). This acceptance was a recognition that, while government representatives may not necessarily agree with all statements in all the authored chapters, they find a wealth of information and valuable assessments in the Technical Chapters of WG3 that will assist future climate negotiations.

\section{James P. Bruce}

(Co-Chair IFOC, WG3)

1875 Juno Avenue,

Ottawa,

Canada K1H $6 S 6$

SIR - It was reported in a recent News story (Nature 378, 329; 1995) that I declined a request from Pat Michaels for detailed output from a climate model, the details of which are cited in the second scientific assessment of the IPCC. $\mathrm{He}$ claimed that he needed the gridpoint data to review the IPCC report. At the time, I sent Michaels the current draft of the paper cited in the IPCC report (and subsequently published in Nature 376, 501; 1995). Michaels had expressed concern that scattering from anthropogenic sulphate aerosols would not diminish the expected warming over the Arctic due to increasing greenhouse gases. So I also sent another preprint, subsequently published in the Journal of Climate (8, 2364-2386; 1995) which explains how the Arctic can be cooled by aerosols, even if they are not located over the Arctic. In accordance with normal practice, the raw data are not normally released until the results are formally published. Hadley Centre model data are the property of the UK Depart- ment of the Environment and not IPCC, and are made freely available to bona fide researchers in due course through the UK Climate Impacts LINK Project.

\section{John F. B. Mitchell}

Hadley Centre for Prediction

and Research,

Meteorological Office,

Bracknell RG12 2SZ,UK

SIR - Aubrey Meyer et al. assert (Nature $\mathbf{3 7 8}, 433 ; 1995$ ) that a chapter should be excluded from the Second Assessment Report (SAR) of the IPCC. The chapter concerns "Social Costs" of climate change and has been prepared by IPCC Working Group 3 (WG3).

This SAR Summary has been approved but the chapter prepared by WG3 disagrees with the summary. Meyer et al. observe that the IPCC procedures do not permit amendment to approved summaries, and they do not like the WG3 chapter. For these reasons, they assert that the chapter should be excluded from the SAR. But the correct amendment would be a change to IPCC procedures, not a change to the SAR. The IPCC summaries should be written and approved only after the work they summarize has been completed.

The IPCC approved the summary of its 1994 Scientific Assessment before that report was written. This resulted in misleading data being 'tailored' to fit the summary in that report. Now, either the summary of the SAR will 'summarize' a chapter that is not in the SAR, or the summary will say the opposite of a chapter that it claims to summarize. Neither of these options should be acceptable to scientists of integrity.

Do the signatories of the letter from Meyer et al. never conduct peer review of other people's work? Would any of them recommend publication of a paper that contained a 'summary' that 'summarized' work not in the paper? And would they recommend publication of a paper that contained a 'summary' stating the opposite of conclusions in the paper?

The IPCC purports to be a scientific organization providing scientific advice to politicians. Many observers have suspected that it is a primarily political organization. The letter from Meyer et al. is all the confirmation they require of their suspicion.

\section{Richard S. Courtney}

31 Rivelands Road,

Swindon Village,

Cheltenham,

Gloucestershire GL51 9RF, UK

\section{Correspondence}

Letters submitted for Correspondence should be typed, double-spaced, on one side of the paper only, or e-mailed to nature@nature.com

\section{Two sides of Spanish science}

SIR - In the past decade, Nature has carried many articles about science in Spain, but it has not previously been remarked that there are two kinds of researchers in Spain. One, which could be called 'Science Citation Index (SCI) scientists', holds the real power in the Spanish scientific community.

These SCI scientists work in such fields as biochemistry, biology, biophysics, chemistry, cytology and histology, endocrinology, immunology, materials science, medicine, neurosciences, optics, physics and spectroscopy. These subjects have in common the ease with which they can be published in SCI ascribed journals because of their widespread interest. SCI scientists do not carry out much field work, they frequently have contacts with overseas researchers and they carry out few educational activities.

The other group, which might be called 'parallel Spanish Scientists', work in areas that are not well developed in SCI journals. They often carry out field work in such areas as agriculture, ecology, engineering, forestry, food science, geography, geology, geosciences, oceanography, ornithology, botany, veterinary sciences and zoology. These parallel Spanish scientists usually work in local areas and publish in serious Spanish journals that are not in the SCI lists. They often know French or German (rather than English) and carry out other activities such as teaching, writing books, organizing meetings or running laboratories.

The easy computerized access to the SCI lists to measure productivity has simplified the government's task in awarding grants, increasing salaries, allocating projects, forming boards of examiners, providing posts for civil servants and so on. SCI productivity is the crucial number that governs the life of all Spanish researchers. This pragmatic transformation of Spanish science, which was accelerated in 1986 when Spain joined what is now the European Union, has two different results: bolstering scientists working in exportable subjects who are obviously happy with this policy, and causing great discontentment among the 'parallel researchers' working in regional and local subjects. In spite of the apparent unfairness of this system, many 'parallel Spanish scientists' are working increasingly on papers included in SCI journals. Meanwhile, we all watch with sadness the decline in quality of contributions to Spanish written journals.

\section{Javier Garcia-Guinea}

Departamento de Geologia,

Museo Nacional de Ciencias Naturales, c/ Jose Gutierrez Abascal 2,

28006 Madrid, Spain 